\title{
The metabolic syndrome and its components in 178 patients treated for craniopharyngioma after 16 years of follow-up
}

\author{
Mark Wijnen 1,2, *, Daniel S Olsson 3,4,*, Marry M van den Heuvel-Eibrink 2,5, *, Casper Hammarstrand 3,4,*, \\ Joseph A M J L Janssen', Aart-Jan van der Lely', Gudmundur Johannsson 3,4,* and Sebastian J C M M Neggers 1,2, * \\ ${ }^{1}$ Department of Medicine, Section Endocrinology, Pituitary Centre Rotterdam, Erasmus University Medical Centre, Rotterdam, \\ the Netherlands, 'Department of Paediatric Oncology/Haematology, Erasmus MC - Sophia Children's Hospital, \\ Rotterdam, the Netherlands, ${ }^{3}$ Department of Internal Medicine and Clinical Nutrition, Institute of Medicine, \\ Sahlgrenska Academy, University of Gothenburg, Gothenburg, Sweden, ${ }^{4}$ Department of Endocrinology, Sahlgrenska \\ University Hospital, Gothenburg, Sweden, and ${ }^{5}$ Princess Maxima Centre for Paediatric Oncology, Utrecht, \\ the Netherlands \\ *(M Wijnen, D S Olsson, M M van den Heuvel-Eibrink, C Hammarstrand, G Johannsson and S J C M M Neggers \\ contributed equally to this work) \\ Correspondence \\ should be addressed \\ to M Wijnen \\ Email \\ m.wijnen.1@erasmusmc.nl
}

\begin{abstract}
Objective: Patients with craniopharyngioma are at an increased risk for cardio- and cerebrovascular mortality. The metabolic syndrome (MetS) is an important cardiometabolic risk factor, but barely studied in patients with craniopharyngioma. We aimed to investigate the prevalence of and risk factors for the MetS and its components in patients with craniopharyngioma.

Design: Cross-sectional study with retrospective data.

Methods: We studied the prevalence of and risk factors for the MetS and its components in 110 Dutch (median age 47 years, range 18-92) and 68 Swedish (median age 50 years, range 20-81) patients with craniopharyngioma with $\geq 3$ years of follow-up (90 females (51\%); 83 patients with childhood-onset craniopharyngioma (47\%); median follow-up after craniopharyngioma diagnosis 16 years (range 3-62)). In Dutch patients aged 30-70 years and Swedish patients aged 45-69 years, we examined the prevalence of the MetS and its components relative to the general population.

Results: Sixty-nine (46\%) of 149 patients with complete data demonstrated the MetS. Prevalence of the MetS was significantly higher in patients with craniopharyngioma compared with the general population ( $40 \%$ vs $26 \%$ $(P<0.05)$ for Dutch patients; $52 \%$ vs $15 \%(P<0.05)$ for Swedish patients). Multivariable logistic regression analysis identified visual impairment as a borderline significant predictor of the MetS (OR $2.54,95 \% \mathrm{Cl} 0.95-6.81 ; P=0.06$ ) after adjustment for glucocorticoid replacement therapy and follow-up duration. Age, female sex, tumor location, radiological hypothalamic damage, ${ }^{90}$ Yttrium brachytherapy, glucocorticoid replacement therapy and follow-up duration significantly predicted components of the MetS.

Conclusions: Patients with craniopharyngioma are at an increased risk for the MetS, especially patients with visual impairment.
\end{abstract}

\section{Introduction}

Craniopharyngiomas are (supra)sellar epithelial tumors that often contain calcifications and fluid-filled cysts. Despite their benign histology, they are associated with significant morbidity due to both tumor and treatment (1). Craniopharyngiomas affect children and adults and are predominantly diagnosed between 5-9 and 40-44 years

Published by Bioscientifica Ltd. 
of age (2). They are usually treated with neurosurgical excision with or without postoperative radiotherapy. Other treatment options include the intracystic appliance of beta-emitting isotopes or chemotherapeutic substances, as well as stereotactic radiosurgery (1). Patients with craniopharyngioma are at increased risk for premature mortality $(3,4,5,6)$. The most important cause of premature mortality in patients with craniopharyngioma is cardio- and cerebrovascular disease, with a reported standardized mortality ratio between 3.2 and 19.4 $(4,5,6)$. The increased risk for cardio- and cerebrovascular mortality in patients with craniopharyngioma is poorly understood but likely to be multifactorial. Tumor- and treatment-related damage of critical neurovascular structures (e.g. hypothalamus, pituitary, optic nerves and carotid arteries), as well as their associated morbidities with currently available management options (e.g. present hormone replacement regimens for hypopituitarism) may be involved.

Studies in the general population identified the metabolic syndrome (MetS) as an important risk factor for cardio- and cerebrovascular disease, as well as type 2 diabetes mellitus (7). The MetS, which was conceptualized by Reaven in 1988 (8), has been associated with a twofold increased risk for cardio- and cerebrovascular disease and a five-fold increased risk for type 2 diabetes mellitus (7). During the last two decades, several definitions of the MetS have been proposed $(9,10,11,12,13,14)$. All these definitions include obesity, insulin resistance, dyslipidemia and elevated blood pressure as their main components. To date, only a few studies assessed the MetS and its components in patients with craniopharyngioma $(15,16,17,18,19,20)$. Small study populations that mainly consist of children, a lack of comparison with the general population and the evaluation of only a few potential risk factors for the MetS and its components are major limitations of these studies.

The objectives of our study were to determine the prevalence of and risk factors for the MetS and its components in patients with craniopharyngioma. In a subset of patients, we examined the prevalence of the MetS and its components in relation to the general population.

\section{Subjects and methods}

\section{Study population}

Patients treated for craniopharyngioma at the Erasmus University Medical Centre (Rotterdam, the Netherlands) and the Sahlgrenska University Hospital (Gothenburg,
Sweden) were eligible for participation in this crosssectional study with retrospective data if they were $\geq 18$ years of age at their last follow-up visit, had $\geq 3$ years of follow-up after craniopharyngioma diagnosis and presented data on $\geq 1$ component of the MetS. A computerbased search in the medical records identified 225 patients with craniopharyngioma of whom 178 were eligible (110 Dutch and 68 Swedish patients). Craniopharyngiomas were diagnosed in 83 patients $(47 \%)$ who were $<18$ years of age (i.e. childhood-onset) and in 95 (53\%) patients who were $\geq 18$ years of age (i.e. adult-onset). All patients gave their informed consent and were included in the study.

In a subset of patients, we examined the prevalence of the MetS, its components and type 2 diabetes mellitus in relation to the general population. This includes Dutch patients aged 30-70 years $(n=73)$ and Swedish patients aged $45-69$ years $(n=29)$. Data from the Dutch general population were reported in the 'Nederland de Maat Genomen' (NL de Maat) study (21); data from the Swedish general population in the 'Life conditions, Stress and Health' (LSH) study (22). In the 'NL de Maat' study, 2059 females and 1806 males from the Dutch general population, aged 30-70 years, were assessed for cardioand cerebrovascular disease risk factors between 2009 and 2010 (21). The 'LSH' study included 505 females and 502 males from the Swedish general population, aged 45-69 years, who were evaluated for cardio- and cerebrovascular disease risk factors between 2003 and 2004 (22). The local institutional review board of the Erasmus University Medical Centre and the regional ethics review board in Gothenburg, Sweden, approved this study.

\section{Data collection}

Data on baseline characteristics, tumor characteristics, craniopharyngioma treatment, recurrence and longterm health outcome were collected from the medical records. Craniopharyngioma location, hydrocephalus and radiological hypothalamic damage were studied as tumor characteristics. Location was classified as intrasellar, suprasellar and both intra-/suprasellar. Radiological hypothalamic damage was defined as tumor- and/or treatment-related injury to the hypothalamus and/or third ventricle as visualized on neuroimaging. Neurosurgery, radiotherapy and ${ }^{90}$ Yttrium brachytherapy were studied as craniopharyngioma treatment modalities. Recurrence was defined as reappearance or re-growth of the craniopharyngioma after the prior treatment. The MetS and parameters 
Table 1 Definition of the MetS (14).

At least three of the following five criteria:
Body mass index $>30 \mathrm{~kg} / \mathrm{m}^{2}$
Fasting glucose $\geq 5.6 \mathrm{mmol} / \mathrm{L}$ or drug treatment for increased
glucose
Triglycerides $\geq 1.7 \mathrm{mmol} / \mathrm{L}$ or drug treatment for elevated
triglycerides
$\mathrm{HDL}$ cholesterol $<1.0 \mathrm{mmol} / \mathrm{L}$ in males and $<1.3 \mathrm{mmol} / \mathrm{L}$ in
females or drug treatment for reduced $\mathrm{HDL}$ cholesterol
Blood pressure $\geq 130 / 85 \mathrm{mmHg}$ or drug treatment for
hypertension

MetS, metabolic syndrome.

reflecting its components (i.e. body mass index, fasting glucose, triglycerides, high-density lipoprotein (HDL) cholesterol, systolic and diastolic blood pressure), presence of and treatment for diabetes mellitus, dyslipidemia, and hypertension, glycated hemoglobin (HbA1c), cardio- and cerebrovascular morbidity, presence of and treatment for hypopituitarism, visual impairment and current treatment for epilepsy and psychiatric illness were studied as conditions reflecting long-term health outcome. The MetS was defined according to the Joint Interim Statement of the International Diabetes Federation Task Force on Epidemiology and Prevention; National Heart, Lung, and Blood Institute; American Heart Association; World Heart Federation; International Atherosclerosis Society; and International Association for the Study of Obesity (Table 1) (14). According to this definition, patients are classified as obese if waist circumference is greater than population- and country-specific definitions or if body mass index is $>30 \mathrm{~kg} / \mathrm{m}^{2}$. As data on waist circumference were unavailable in our patients, we classified patients as obese by body mass index only. Pituitary hormone deficiencies were diagnosed by formal pituitary function testing in all patients. Based on clinical guidelines and shared decision making growth hormone replacement therapy (GHRT) was started. Sex steroid replacement therapy was discontinued in females when a physiological menopausal age (i.e. approximately 51 years) was reached. Visual impairment was defined as a decreased visual acuity after correction for refraction disorders and/or as the presence of a visual field defect.

\section{Statistical analysis}

Statistical analyses were conducted using the Statistical Package for Social Sciences (SPSS 24). Evaluations were based on the number of patients with available data. Continuous and categorical variables were compared using Student's $t$-tests and Chi-square tests respectively. Non-parametric equivalent tests were used when assumptions were not met. Prevalence of the MetS, its components and type 2 diabetes mellitus were compared between patients with craniopharyngioma and the general population using one-sample proportion tests. Logistic regression analyses were performed to identify risk factors for the MetS and its components. Age, sex, age group at craniopharyngioma diagnosis, tumor location, hydrocephalus, radiological hypothalamic damage, radiotherapy, ${ }^{90}$ Yttrium brachytherapy, craniopharyngioma recurrence, panhypopituitarism, treatment of growth hormone deficiency (GHD), hypogonadotropic hypogonadism, secondary adrenal insufficiency, secondary hypothyroidism and diabetes insipidus, as well as visual impairment and treatment for epilepsy and psychiatric illness were evaluated as potential risk factors. Variables statistically significant in univariable regression (i.e. a $P$ value $<0.05$ (two-tailed)) were further evaluated by multivariable regression. All multivariable regression analyses were adjusted for follow-up duration.

\section{Results}

\section{Patient characteristics}

We evaluated 178 patients (90 females (51\%)) with craniopharyngioma (Table 2). Median follow-up after craniopharyngioma diagnosis was 16 years (range 3-62). Median age at last follow-up assessment was 47 years (range 18-92) (i.e. median 47 years (range 18-92) in Dutch patients, and median 50 years (range 20-81) in Swedish patients). Patient characteristics were similar in females and males, except for secondary hypothyroidism (88\% vs $97 \%$; $P<0.05)$. GHRT was used by $117(79 \%)$ patients with GHD. Thirty-five (30\%) of these patients used GHRT during childhood. Sex steroid replacement therapy was used by 122 (95\% of males and premenopausal females) patients with hypogonadotropic hypogonadism. All premenopausal females on sex steroid replacement therapy used regular oral estrogen-progestin replacement regimens. Three males did not use sex steroid replacement therapy due to prostate cancer. All patients with secondary adrenal insufficiency, secondary hypothyroidism and diabetes insipidus were adequately treated with hormone replacement therapy. Glucocorticoid replacement therapy was used by 145 (82\%) patients. The median daily hydrocortisone equivalent dose in these patients was $20 \mathrm{mg}$ (range $5-50$ ). Antiepileptic drugs were used by 15 (8\%) patients; psychiatric drugs (i.e. antipsychotics, 
Table 2 Patient characteristics.

\begin{tabular}{|c|c|c|c|}
\hline & All craniopharyngiomas $(n=178)$ & Females $(n=90)$ & Males $(n=88)$ \\
\hline \multicolumn{4}{|l|}{ Baseline characteristics } \\
\hline Age at diagnosis (years) ${ }^{a}$ & $23(0-79)$ & $23(4-73)$ & $24(0-79)$ \\
\hline Childhood-onset $(n(\%))$ & $83(47)$ & $40(44)$ & $43(49)$ \\
\hline Adult-onset $(n(\%))$ & $95(53)$ & $50(56)$ & $45(51)$ \\
\hline Follow-up since diagnosis (years) ${ }^{a}$ & $16(3-62)$ & $16(3-62)$ & $18(3-48)$ \\
\hline Age at last follow-up assessment (years) ${ }^{a}$ & $47(18-92)$ & $48(18-82)$ & $47(18-92)$ \\
\hline \multicolumn{4}{|l|}{ Tumor characteristics } \\
\hline \multicolumn{4}{|l|}{ Location $(n(\%))$} \\
\hline Intrasellar & $4(2)$ & $1(1)$ & $3(4)$ \\
\hline Suprasellar & $67(40)$ & $34(41)$ & $33(40)$ \\
\hline Intra-/suprasellar & $95(57)$ & $49(58)$ & $46(52)$ \\
\hline Hydrocephalus (n (\%)) & $47(27)$ & $26(29)$ & $21(24)$ \\
\hline Radiological hypothalamic damage $(n(\%))$ & $65(39)$ & $31(37)$ & $34(42)$ \\
\hline \multicolumn{4}{|l|}{ Craniopharyngioma treatment } \\
\hline Neurosurgery $(n(\%))$ & $165(93)$ & $84(93)$ & $81(92)$ \\
\hline Radiotherapy (n (\%)) & $85(48)$ & $43(48)$ & $42(48)$ \\
\hline${ }^{90}$ Yttrium brachytherapy ( $\left.n(\%)\right)$ & $29(16)$ & $16(18)$ & $13(15)$ \\
\hline Recurrence $(n(\%))$ & $70(40)$ & $36(40)$ & $34(40)$ \\
\hline \multicolumn{4}{|l|}{ Long-term health outcome } \\
\hline \multicolumn{4}{|l|}{ Pituitary hormone deficiencies $(n(\%))$} \\
\hline $\mathrm{GH}$ & $148(85)^{b}$ & $73(82)$ & $75(88)$ \\
\hline $\mathrm{FSH} / \mathrm{LH}$ & $155(88)^{c}$ & $76(84)$ & $79(91)$ \\
\hline ACTH & $145(82)^{d}$ & $69(77)$ & $76(86)$ \\
\hline TSH & $163(92)^{d}$ & $78(88)$ & $85(97)$ \\
\hline $\mathrm{ADH}$ & $111(62)^{d}$ & $55(61)$ & $56(64)$ \\
\hline Panhypopituitarism & $93(53)$ & $46(51)$ & $47(54)$ \\
\hline Visual impairment $(n(\%))$ & $126(78)$ & $63(77)$ & $63(80)$ \\
\hline Body mass index $\left(\mathrm{kg} / \mathrm{m}^{2}\right)^{\mathrm{a}}$ & $30.1(16.9-59.5)$ & $30.4(20.3-59.5)$ & $30.1(16.9-49.1)$ \\
\hline Treatment for epilepsy $(n(\%))$ & $15(8)$ & $5(6)$ & $10(11)$ \\
\hline Treatment for psychiatric illness ( $n(\%))$ & $24(14)$ & $11(13)$ & $13(15)$ \\
\hline
\end{tabular}

a Median (range). b GHRT was used by 117 patients with GHD (79\%). cSex steroid replacement therapy was used by 122 patients with hypogonadotropic hypogonadism ( $95 \%$ of males and premenopausal females). dAll patients were adequately treated with hormone replacement therapy.

$\mathrm{ACTH}$, adrenocorticotropic hormone; $\mathrm{ADH}$, antidiuretic hormone; $\mathrm{FSH} / \mathrm{LH}$, follicle stimulating hormone/luteinizing hormone; GH, growth hormone; GHD, growth hormone deficiency; GHRT, growth hormone replacement therapy; $\mathrm{kg} / \mathrm{m}^{2}$, kilograms per square meter; $n$, number; TSH, thyroid-stimulating hormone.

antidepressants, or benzodiazepines) by $24 \quad(14 \%)$ patients. One patient was known with type 1 diabetes mellitus; another patient had gestational diabetes. These two patients were excluded from the analyses on the MetS and its components.

Patient characteristics in Dutch compared with Swedish patients with craniopharyngioma, patients with childhoodonset compared with adult-onset craniopharyngioma, patients with treated compared with untreated GHD and patients with obesity compared to patients without obesity are shown in Supplementary Table 1 (see section on supplementary data given at the end of this article).

\section{The MetS and its components}

In our study, 69 (46\%) of 149 patients with complete data demonstrated the MetS (Table 3). Twenty patients (29\%) had three components of the MetS, 30 (43\%) patients had four components and 14 (20\%) patients had five components. In $5(7 \%)$ patients with the MetS the exact number of components was unknown. Obesity was present in 84 (52\%) patients. Increased fasting glucose affected 57 (37\%) patients; elevated triglycerides 80 (54\%) patients. Reduced HDL cholesterol was found in 65 (46\%) patients; and elevated blood pressure in 96 (56\%) patients. In the subset of patients who were compared with the general population (i.e. Dutch patients aged 30-70 years and Swedish patients aged 45-69 years), prevalence of the MetS was significantly higher in patients with craniopharyngioma $(40 \%$ vs $29 \%(P<0.05)$ for Dutch patients; $52 \%$ vs $15 \%(P<0.05)$ for Swedish patients). Prevalence of obesity, reduced HDL cholesterol and elevated blood pressure were also significantly higher in Dutch and Swedish patients with craniopharyngioma compared with the general population. Prevalence of elevated triglycerides could only be compared with the general population in Swedish patients with craniopharyngioma. In this subgroup, prevalence of 
elevated triglycerides was significantly higher in patients with craniopharyngioma (Table 3).

Prevalence of the MetS and its components were similar in Dutch and Swedish patients with craniopharyngioma, except for increased fasting glucose, which was significantly more common in Swedish compared with Dutch patients $(47 \%$ vs $29 \%$; $P<0.05)$ (Table 3$)$. Female patients had a significantly higher prevalence of reduced HDL cholesterol $(58 \%$ vs $35 \% ; P<0.05)$ and elevated blood pressure $(64 \%$ vs $47 \% ; P<0.05)$ compared with male patients. Elevated blood pressure was significantly more common in patients with adult-onset compared with childhood-onset craniopharyngioma ( $64 \%$ vs $46 \%$; $P<0.05)$. There were no significant differences in the MetS and its components between patients with treated and untreated GHD (Table 4).

\section{Risk factors for the MetS and its components in patients with craniopharyngioma}

Results of the univariable and multivariable logistic regression analyses on risk factors for the MetS are shown in Table 5. Glucocorticoid replacement therapy (OR: 3.27, 95\% CI: $1.22-8.74 ; P<0.05)$ and visual impairment (OR: 2.63, 95\% CI: $1.11-6.24 ; P<0.05)$ were identified as significant risk factors for the MetS in the univariable analyses. In the multivariable analysis, visual impairment was borderline significantly associated with the MetS (OR: 2.54, 95\% CI: 0.95-6.81; $P=0.06$ ) after adjustment for glucocorticoid replacement therapy and follow-up duration. Radiological hypothalamic damage was identified as a significant risk factor for obesity (OR: 9.86, 95\% CI: 1.59-61.1; $P<0.05$ ) after adjustment for age, ${ }^{90}$ Yttrium brachytherapy, craniopharyngioma recurrence, vasopressin treatment, panhypopituitarism, treatment for psychiatric illness and follow-up duration. A prolonged follow-up duration significantly decreased the risk for increased fasting glucose (OR: 0.93, 95\% CI: 0.88-0.97; $P<0.05$ ). Intrasellar tumor location significantly protected for elevated triglycerides (OR: 0.43, 95\% CI: 0.21-0.88; $P<0.05$ ) after adjustment for age and follow-up duration. Female sex (OR: 3.29, 95\% CI: $1.35-8.01 ; P<0.05),{ }^{90}$ Yttrium brachytherapy (OR: 7.87, 95\% CI: 1.58-39.2; $P<0.05$ ) and glucocorticoid replacement therapy (OR: 4.80, 95\% CI: $1.12-20.6$; $P<0.05$ ) were identified as significant risk factors for reduced HDL cholesterol after adjustment for hydrocephalus, craniopharyngioma recurrence and follow-up duration. Age (OR: $1.06,95 \%$ CI: $1.02-1.10 ; P<0.05)$ significantly predicted elevated blood pressure after adjustment for 
Table 4 The MetS, its components, type 2 diabetes mellitus, and cardio- and cerebro-vascular morbidity in subgroups.

MetS and its components
MetS
Obesity
Increased fasting glucose
Elevated triglycerides
Reduced HDL cholesterol
Elevated blood pressure
Type 2 diabetes mellitus and cardio
Type 2 diabetes mellitus
HbA1c (mmol/mol)
Myocardial infarction
Cerebrovascular accident

\begin{tabular}{|c|c|}
\hline ㅇ vs $0^{+}$ & $P$ value \\
\hline $54 \%$ vs $40 \%$ & 0.09 \\
\hline $56 \%$ vs $48 \%$ & 0.35 \\
\hline $32 \%$ vs $41 \%$ & 0.26 \\
\hline $59 \%$ vs $49 \%$ & 0.20 \\
\hline $58 \%$ vs $35 \%$ & $<0.05$ \\
\hline $64 \%$ vs $47 \%$ & $<0.05$ \\
\hline
\end{tabular}

- and cerebro-vascular morbidity

\begin{tabular}{cc}
$14 \%$ vs $13 \%$ & 0.70 \\
35 vs 34 & 0.74 \\
$4 \%$ vs $2 \%$ & 0.68 \\
$9 \%$ vs $8 \%$ & 0.82 \\
\hline
\end{tabular}

\begin{tabular}{c}
\hline CO vs $\mathbf{A O}$ \\
\hline $48 \%$ vs $45 \%$ \\
$59 \%$ vs $45 \%$ \\
$33 \%$ vs $39 \%$ \\
$47 \%$ vs $60 \%$ \\
$51 \%$ vs $42 \%$ \\
$46 \%$ vs $64 \%$ \\
$11 \%$ vs $16 \%$ \\
33 vs 36 \\
$1 \%$ vs $5 \%$ \\
$7 \%$ vs $10 \%$ \\
\hline
\end{tabular}

\begin{tabular}{c}
\hline $\boldsymbol{P}$ value \\
\hline \\
0.71 \\
0.08 \\
0.44 \\
0.12 \\
0.28 \\
$<0.05$ \\
\\
0.34 \\
0.15 \\
0.22 \\
0.59 \\
\hline
\end{tabular}

\begin{tabular}{|c|c|}
\hline GHRT vs non-GHRT & $P$ value \\
\hline $43 \%$ vs $57 \%$ & 0.24 \\
\hline $57 \%$ vs $43 \%$ & 0.19 \\
\hline $33 \%$ vs $40 \%$ & 0.49 \\
\hline $51 \%$ vs $58 \%$ & 0.51 \\
\hline $47 \%$ vs $38 \%$ & 0.47 \\
\hline $52 \%$ vs $67 \%$ & 0.16 \\
\hline $10 \%$ vs $23 \%$ & 0.08 \\
\hline 34 vs 37 & 0.72 \\
\hline $2 \%$ vs $7 \%$ & 0.19 \\
\hline $6 \%$ vs $16 \%$ & 0.13 \\
\hline
\end{tabular}

${ }^{a}$ Median (range). b Data available in 118 patients.

\&, female; ${ }^{\dagger}$, male; $\mathrm{AO}$, adult-onset craniopharyngioma; $\mathrm{CO}$, childhood-onset craniopharyngioma; GHRT, treated growth hormone deficiency; HbA1C, glycated hemoglobin; HDL, high-density lipoprotein; MetS, metabolic syndrome; non-GHRT, untreated growth hormone deficiency.

female sex, childhood-onset craniopharyngioma and follow-up duration.

Since visual impairment was identified as a borderline significant predictor for the MetS (i.e. our primary study outcome), we compared baseline, tumor and treatment characteristics, as well as long-term health outcome between patients with and without visual impairment (Table 6). Craniopharyngioma treatment with ${ }^{90}$ Yttrium brachytherapy (21\% vs $6 \%$; $P<0.05)$ and tumor recurrence $(47 \%$ vs $17 \% ; P<0.05$ ) were significantly more frequent in patients with visual impairment compared to those with no visual impairment.

\section{Type 2 diabetes mellitus and cardio- and cerebro- vascular morbidity}

In our study, 24 (14\%) patients suffered from type 2 diabetes mellitus (Table 3) and 11 of them received insulin treatment. In the subset of patients who were compared with the general population, prevalence of type 2 diabetes mellitus was significantly higher in patients

Table 5 Risk factors for the MetS in patients with craniopharyngioma.

\begin{tabular}{|c|c|c|c|c|}
\hline \multirow[b]{2}{*}{ Parameters } & \multicolumn{2}{|c|}{ Univariable analysis } & \multicolumn{2}{|c|}{ Multivariable analysis ${ }^{c, d}$} \\
\hline & Odds ratio $(95 \% \mathrm{Cl})$ & $P$ value & Odds ratio $(95 \% \mathrm{Cl})$ & $P$ value \\
\hline Age (in years) & $1.01(0.99-1.03)$ & 0.22 & & \\
\hline Female sex & $1.69(0.89-3.23)$ & 0.11 & & \\
\hline Childhood-onset disease & $1.10(0.58-2.09)$ & 0.78 & & \\
\hline \multicolumn{5}{|l|}{ Tumor location ${ }^{a}$} \\
\hline Suprasellar & $1.15(0.15-8.71)$ & 0.89 & & \\
\hline Intra-/suprasellar & $0.70(0.09-5.20)$ & 0.72 & & \\
\hline Hydrocephalus & $1.43(0.69-2.98)$ & 0.34 & & \\
\hline Radiological hypothalamic damage & $1.49(0.76-2.94)$ & 0.25 & & \\
\hline Radiotherapy & $1.29(0.68-2.46)$ & 0.43 & & \\
\hline${ }^{90}$ Yttrium brachytherapy & $2.61(0.99-6.89)$ & 0.05 & & \\
\hline Craniopharyngioma recurrence & $1.44(0.74-2.77)$ & 0.28 & & \\
\hline Panhypopituitarism & $1.43(0.75-2.73)$ & 0.28 & & \\
\hline Treatment of GHD & $0.58(0.24-1.45)$ & 0.24 & & \\
\hline Sex steroid replacement ${ }^{b}$ & $2.57(0.26-25.5)$ & 0.42 & & \\
\hline Glucocorticoid replacement & $3.27(1.22-8.74)$ & $<0.05$ & $2.32(0.80-6.73)$ & 0.12 \\
\hline Thyroid hormone replacement & $2.72(0.53-13.9)$ & 0.23 & & \\
\hline Vasopressin treatment & $1.27(0.65-2.48)$ & 0.49 & & \\
\hline Visual impairment & $2.63(1.11-6.24)$ & $<0.05$ & $2.54(0.95-6.81)$ & 0.06 \\
\hline Treatment for epilepsy & $0.82(0.25-2.69)$ & 0.74 & & \\
\hline Treatment for psychiatric illness & $0.46(0.18-1.19)$ & 0.11 & & \\
\hline
\end{tabular}


Table 6 Comparison of patients with and without visual impairment.

\begin{tabular}{|c|}
\hline \multirow{2}{*}{$\begin{array}{l}\text { Baseline characteristics } \\
\quad \wp(n(\%))\end{array}$} \\
\hline \\
\hline ô $(n(\%))$ \\
\hline Age at diagnosis (years) ${ }^{a}$ \\
\hline Childhood-onset $(n(\%))$ \\
\hline Adult-onset $(n(\%))$ \\
\hline Follow-up since diagnosis (years) ${ }^{a}$ \\
\hline Age at last follow-up assessment (years) ${ }^{a}$ \\
\hline Tumor characteristics \\
\hline Location $(n(\%))$ \\
\hline Intrasellar \\
\hline Suprasellar \\
\hline Intra-/suprasellar \\
\hline Hydrocephalus ( $n(\%)$ ) \\
\hline Radiological hypothalamic damage $(n(\%))$ \\
\hline Craniopharyngioma treatment \\
\hline Neurosurgery $(n(\%))$ \\
\hline Radiotherapy (n (\%)) \\
\hline${ }^{90}$ Yttrium brachytherapy $(n(\%))$ \\
\hline Recurrence $(n(\%))$ \\
\hline Long-term health outcome \\
\hline Pituitary hormone deficiencies ( $n(\%))$ \\
\hline $\mathrm{GH}$ \\
\hline $\mathrm{FSH} / \mathrm{LH}$ \\
\hline АСТН \\
\hline TSH \\
\hline $\mathrm{ADH}$ \\
\hline Panhypopituitarism \\
\hline Body mass index $\left(\mathrm{kg} / \mathrm{m}^{2}\right)^{a}$ \\
\hline Treatment for epilepsy ( $n(\%))$ \\
\hline Treatment for psychiatric illness ( $n(\%))$ \\
\hline MetS and its components \\
\hline MetS $(n(\%))$ \\
\hline Obesity $(n(\%))$ \\
\hline Increased fasting glucose $(n(\%))$ \\
\hline Elevated triglycerides $(n(\%))$ \\
\hline Reduced HDL cholesterol ( $n(\%))$ \\
\hline Elevated blood pressure $(n(\%))$ \\
\hline
\end{tabular}

\begin{tabular}{c}
\hline Visual impairment $(n=126)$ \\
\hline $63(50)$ \\
$63(50)$ \\
$26(0-79)$ \\
$59(47)$ \\
$67(53)$ \\
$16(3-62)$ \\
$48(18-92)$ \\
\\
$3(3)$ \\
$49(41)$ \\
$67(56)$ \\
$38(30)$ \\
$46(39)$ \\
$120(95)$ \\
$64(51)$ \\
$27(21)$ \\
$59(47)$ \\
\end{tabular}

\begin{tabular}{c}
\hline No visual impairment $(n=35)$ \\
\hline $19(54)$ \\
$16(46)$ \\
$17(5-61)$ \\
$16(46)$ \\
$19(54)$ \\
$17(6-39)$ \\
$47(18-81)$
\end{tabular}

\begin{tabular}{r}
\hline P value \\
\hline \\
0.65 \\
0.26 \\
0.91 \\
0.49 \\
0.71 \\
0.88 \\
1.00 \\
0.62 \\
0.66 \\
0.14 \\
0.84 \\
\\
0.23 \\
0.26 \\
$<0.05$ \\
$<0.05$
\end{tabular}

aMedian (range).

\$, female; ô, male; $A C T H$, adrenocorticotropic hormone; $A D H$, antidiuretic hormone; $F S H / L H$, follicle stimulating hormone/luteinizing hormone; GH, growth hormone; GHD, growth hormone deficiency; GHRT, growth hormone replacement therapy; HDL, high-density lipoprotein; $\mathrm{kg} / \mathrm{m}^{2}$, kilograms per square meter; MetS, metabolic syndrome; $n$, number; TSH, thyroid-stimulating hormone.

with craniopharyngioma $(11 \%$ vs $6 \%(P<0.05)$ for Dutch patients; $17 \%$ vs $6 \%(P<0.05)$ for Swedish patients). In our study, $6(3 \%)$ patients with craniopharyngioma experienced a myocardial infarction, and 15 (8\%) patients suffered from a cerebrovascular accident. One patient with childhood-onset craniopharyngioma had a myocardial infarction at the age of 38 years. In patients with adult-onset craniopharyngioma, the median age at myocardial infarction was 53 years (range: 32-73 years). Cerebrovascular accidents affected six patients with childhood-onset craniopharyngioma at a median age of 31 years (range: 19-38). The median age of cerebrovascular accident in patients with adult-onset craniopharyngioma was 64 years (range: 35-77). Prevalence of type 2 diabetes mellitus, myocardial infarction and cerebrovascular accident, as well as HbA1c levels were similar in Dutch and Swedish patients with craniopharyngioma (Table 3), as well as in females and males, patients with childhoodonset and adult-onset craniopharyngioma, and patients with treated and untreated GHD (Table 4).

\section{Discussion}

We performed the largest study that investigated the MetS and its components in patients with craniopharyngioma to 
date. After a median follow-up duration of 16 years, almost half of the patients with craniopharyngioma demonstrated the MetS. Accordingly, in a subset of Dutch and Swedish patients who were compared with the general population, we found that the MetS was significantly more prevalent than expected. Using multivariable logistic regression analyses adjusted for follow-up duration, we identified visual impairment, radiological hypothalamic damage, tumor location, female sex, ${ }^{90}$ Yttrium brachytherapy, glucocorticoid replacement therapy and age as significant risk factors for the MetS and its components.

In our study, prevalence of the MetS in patients with craniopharyngioma was $46 \%$. Other studies that investigated the MetS in patients with craniopharyngioma observed a prevalence between 8 and $67 \%$ (Table 7) $(15,16$, $17,18,19,20)$. This wide variation in prevalence may be related to heterogeneity in study populations and difference in definitions used to classify patients as exhibiting the MetS. In the subset of Dutch and Swedish patients with craniopharyngioma who were compared with the general population, we observed a significantly higher prevalence of the MetS than expected. This is in concordance with three small other studies that also compared the prevalence of the MetS between patients with craniopharyngioma and control subjects $(15,17,18)$. Studies that investigated the MetS in patients with hypopituitarism due to various causes (including craniopharyngioma) did not observe any significant difference in the prevalence of the MetS between patients with craniopharyngioma and patients with hypopituitarism due to other causes, at least in patients with untreated GHD $(18,23,24)$. Profka et al. observed that the beneficial metabolic effects of GHRT were less pronounced in patients with craniopharyngioma compared with patients with hypopituitarism due to nonfunctioning pituitary adenoma. In their study, prevalence of the MetS was significantly higher in patients with craniopharyngioma compared with patients with nonfunctioning pituitary adenoma after 5 years of GHRT (37\% vs $5 \% ; P<0.05)(18)$.

The increased susceptibility for the MetS and its components in patients with craniopharyngioma is likely to be multifactorial. Tumor- and treatment-related damage of important brain structures, as well as their associated morbidities with currently available management options may altogether adversely affect metabolic function. This makes it challenging to evaluate risk factors for the MetS and its components. Nevertheless, we assessed patients with craniopharyngioma for predictors of an adverse metabolic state. Using multivariable logistic regression analyses adjusted for follow-up duration, we identified visual impairment as a borderline significant risk factor for the MetS. Radiological hypothalamic damage significantly increased the risk for obesity. A prolonged follow-up duration significantly decreased the risk for increased fasting glucose. Intrasellar tumor location significantly protected for elevated triglycerides. Female sex, ${ }^{90}$ Yttrium brachytherapy and glucocorticoid replacement therapy were identified as significant risk factors for reduced HDL cholesterol. Age significantly predicted elevated blood pressure. The increased risk for the MetS associated with visual impairment may be due to a negative effect of visual impairment on the ability to participate in physical activity. This is illustrated by studies that observed a significantly lower level of physical activity in patients with craniopharyngioma compared with age-matched, sex- matched and body mass index-matched control subjects $(25,26)$. A lower level of physical activity has been associated with an increased risk for the MetS in the general population (27). Differences in tumor characteristics between patients with and without visual impairment may also contribute to the increased risk for the MetS in patients with visual impairment. We found a significantly higher rate of craniopharyngioma recurrence and subsequent treatment with ${ }^{90}$ Yttrium brachytherapy in patients with visual impairment compared to those without visual impairment. Craniopharyngioma recurrence and additional treatment may exacerbate tumor- and treatment-related brain damage, thereby increasing the risk for the MetS and its components.

The increased risk for obesity associated with radiological hypothalamic damage may be due to acquired leptin and insulin resistance, as well as autonomic nervous system dysfunction. These factors may adversely affect food intake and energy expenditure, thereby promoting obesity (28). An increased risk for obesity in patients with craniopharyngioma associated with hypothalamic damage has also been observed in other studies $(29,30$, 31,32 ). We observed an increased risk for reduced HDL cholesterol associated with female sex. This may be due to currently used estrogen-progestin replacement regimens that do not fully simulate the physiological menstrual cycle (33). This is illustrated by a recent study that observed an improved cardiovascular risk profile in premature ovarian insufficient females treated with a more physiological transdermal/transvaginal estrogenprogestin replacement regimen compared with a regular oral estrogen-progestin replacement regimen (34). In our study, all premenopausal females with hypogonadotropic hypogonadism used a regular oral estrogen-progestin replacement regimen. The increased risk for reduced HDL 
Table 7 Studies investigating the MetS in patients with craniopharyngioma.

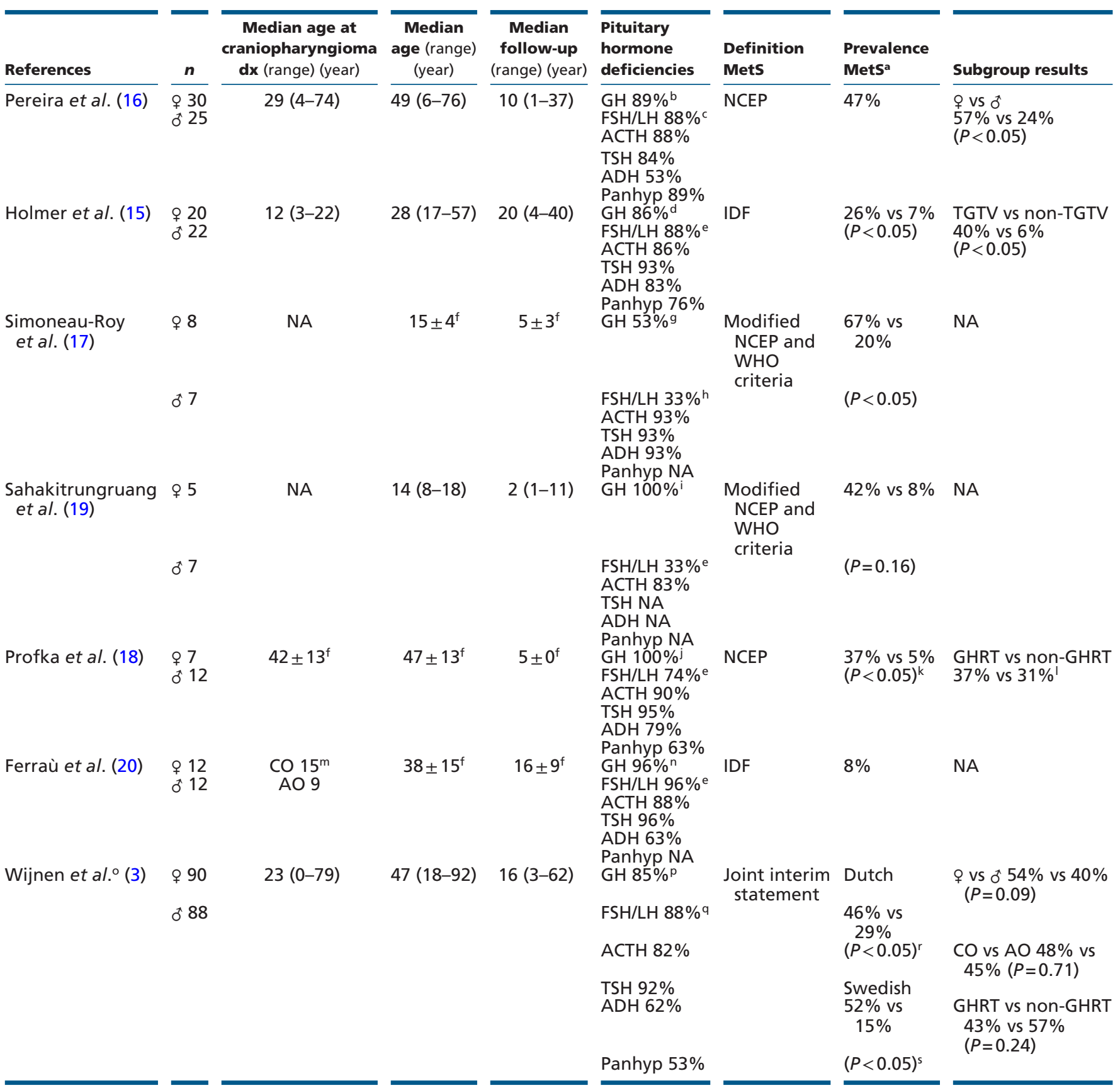

a Compared with control subjects. ${ }^{b}$ Majority of patients with GHD received no GHRT (exact number of patients not mentioned). ${ }^{\mathrm{c} N u m b e r}$ of patients receiving sex steroid replacement therapy not mentioned. ${ }^{\mathrm{d}} 95 \%$ of patients with GHD received GHRT. ${ }^{\mathrm{e}} \mathrm{All}$ patients with hypogonadotropic hypogonadism received sex steroid replacement therapy. ${ }^{f} M e a n \pm$ s.D. ${ }^{9} \mathrm{GHD}$ not formally tested; only (pre)pubertal patients with growth failure received GHRT. hNot mentioned how many patients exhibited hypogonadotropic hypogonadism; $33 \%$ of all patients received sex steroid replacement therapy. iNo patients with GHD received GHRT. ${ }^{\mathrm{i}}$ All patients with GHD received GHRT. ${ }^{k}$ Compared with patients with non-functioning pituitary adenoma. 'Prevalence of the MetS after five years of GHRT compared with baseline before the start of GHRT. ${ }^{m}$ Childhood-onset defined as $\leq 18$ years at craniopharyngioma diagnosis. ${ }^{n} 70 \%$ of patients with GHD received GHRT. ${ }^{\circ}$ Present study. ${ }^{\mathrm{p} 79 \%}$ of patients with GHD received GHRT. $995 \%$ of patients with hypogonadotropic hypogonadism received sex steroid replacement therapy. 'Subset of Dutch patients with craniopharyngioma aged 30-70 years compared with the general population. 'Subset of Swedish patients with craniopharyngioma aged 45-69 years compared with the general population. \&, female; $\$$, male; $\mathrm{ACTH}$, adrenocorticotropic hormone; $\mathrm{ADH}$, antidiuretic hormone; $\mathrm{AO}$, adult-onset craniopharyngioma; $\mathrm{CO}$, childhood-onset craniopharyngioma; dx, diagnosis; FSH/LH, follicle stimulating hormone/luteinizing hormone; GH, growth hormone; GHD, growth hormone deficiency; GHRT, growth hormone replacement therapy; IDF, International Diabetes Federation; MetS, metabolic syndrome; $n$, number; NA, not available; NCEP, National Cholesterol Education Program; Panhyp, panhypopituitarism; TGTV, tumor growth into third ventricle; TSH, thyroid stimulating hormone; WHO, World Health Organization. 
cholesterol associated with glucocorticoid replacement therapy may be due to currently available glucocorticoid replacement regimens that contain relatively high glucocorticoid doses and are administered in patterns that do not fully simulate the physiological circadian cortisol rhythm in terms of serum level and pulsatility (35).

Some limitations of our study should be considered. Data on waist circumference were unavailable. This may have led to an underestimation of the prevalence of the MetS and obesity, because those patients with an elevated waist circumference but body mass index $\leq 30 \mathrm{~kg} / \mathrm{m}^{2}$ were misclassified as non-obese. However, we anticipate that this misclassification is small, since several studies advocated that a body mass index of $>30 \mathrm{~kg} / \mathrm{m}^{2}$ may be used to diagnose obesity as a component of the MetS instead of elevated waist circumference $(14,36,37)$. Moreover, a recent study by Gierach et al. reported a high and significant correlation between body mass index and waist circumference in patients with the MetS $(R=0.78 ; P<0.01)$ (38). The 'NL de Maat' study and 'LSH' study, which were used for the comparisons with the general population, classified participants as obese by waist circumference (21, 22). Otherwise, there were no substantial differences in the criteria used to define the MetS and its components between our study and the 'NL de Maat' study and 'LSH' study. Unfortunately, both the 'NL de Maat' study and 'LSH' study did not report data on increased fasting glucose. Therefore, we were unable to study the prevalence of increased fasting glucose in patients with craniopharygioma relative to the general population. Another limitation of our study is that we were unable to investigate the prevalence of the MetS relative to the general population after adjustment for obesity. Interestingly, when analyzing our data, the prevalence of the MetS seems to be lower than the prevalence of obesity in patients with craniopharyngioma, while in the Dutch general population the prevalence of the MetS seems to be higher than the prevalence of obesity. Since visceral adipose tissue-induced insulin resistance is postulated to be the principal factor resulting in the MetS and its components (7), this indicates that one may expect an even higher prevalence of the MetS in patients with craniopharyngioma. Future studies should clarify this issue. Other limitations of our study include the unavailability of data on ethnicity, lifestyle factors, histological subtype of craniopharyngioma (i.e. adamantinomatous or papillary) and body composition measured by dual-energy X-ray absorptiometry (DXA). Body composition measured by DXA has been shown to be a better predictor for cardioand cerebrovascular morbidity than body composition measured by anthropometry $(39,40)$.
In conclusion, we observed a high prevalence of the MetS and its components in patients with craniopharyngioma. In a subset of Dutch and Swedish patients with craniopharyngioma who were compared with the general population, we found that the MetS was significantly more prevalent than expected. Using multivariable logistic regression analyses adjusted for follow-up duration, we identified visual impairment, radiological hypothalamic damage, tumor location, female sex, ${ }^{90}$ Yttrium brachytherapy, glucocorticoid replacement therapy and age as significant risk factors for the MetS and its components in patients with craniopharyngioma.

\section{Supplementary data}

This is linked to the online version of the paper at https://doi.org/10.1530/ EJE-17-0387.

\section{Declaration of interest}

The authors declare that there is no conflict of interest that could be perceived as prejudicing the impartiality of the research reported.

\section{Funding}

This research did not receive any specific grant from any funding agency in the public, commercial or not-for-profit sector.

\section{Acknowledgements}

The authors would like to thank the physicians involved in the treatment and follow-up care of our patients.

\section{References}

1 Muller HL. Craniopharyngioma. Endocrine Reviews 201435 513-543. (https://doi.org/10.1210/er.2013-1115)

2 Nielsen EH, Feldt-Rasmussen U, Poulsgaard L, Kristensen LO, Astrup J, Jorgensen JO, Bjerre P, Andersen M, Andersen C, Jorgensen $\mathrm{J}$ et al. Incidence of craniopharyngioma in Denmark $(\mathrm{n}=189)$ and estimated world incidence of craniopharyngioma in children and adults. Journal of Neurooncology 2011104 755-763. (https://doi. org/10.1007/s11060-011-0540-6)

3 Wijnen M, van den Heuvel-Eibrink MM, Janssen JA, CatsmanBerrevoets CE, Michiels EM, van Veelen-Vincent MC, Dallenga AH, van den Berge JH, van Rij CM, Van der Lely AJ et al. Very long-term sequelae of craniopharyngioma. European Journal of Endocrinology 2017176 755-767. (https://doi.org/10.1530/EJE-17-0044)

4 Bulow B, Attewell R, Hagmar L, Malmstrom P, Nordstrom CH \& Erfurth EM. Postoperative prognosis in craniopharyngioma with respect to cardiovascular mortality, survival, and tumor recurrence. Journal of Clinical Endocrinology and Metabolism 199883 3897-3904. (https://doi.org/10.1210/jcem.83.11.5240)

5 Tomlinson JW, Holden N, Hills RK, Wheatley K, Clayton RN, Bates AS, Sheppard MC \& Stewart PM. Association between premature mortality and hypopituitarism. West Midlands Prospective Hypopituitary Study Group. Lancet 2001357 425-431. (https://doi. org/10.1016/S0140-6736(00)04006-X) 
6 Olsson DS, Andersson E, Bryngelsson IL, Nilsson AG \& Johannsson G. Excess mortality and morbidity in patients with craniopharyngioma, especially in patients with childhood onset: a population-based study in Sweden. Journal of Clinical Endocrinology and Metabolism 2015100 467-474. (https://doi.org/10.1210/jc.2014-3525)

7 Cornier MA, Dabelea D, Hernandez TL, Lindstrom RC, Steig AJ, Stob NR, Van Pelt RE, Wang H \& Eckel RH. The metabolic syndrome. Endocrine Reviews 200829 777-822. (https://doi.org/10.1210/er.2008-0024)

8 Reaven GM. Banting lecture 1988. Role of insulin resistance in human disease. Diabetes 198837 1595-1607. (https://doi.org/10.2337/ diab.37.1.28)

9 Alberti KG \& Zimmet PZ. Definition, diagnosis and classification of diabetes mellitus and its complications. Part 1: diagnosis and classification of diabetes mellitus provisional report of a WHO consultation. Diabetic Medicine 199815 539-553. (https:// doi.org/10.1002/(SICI)1096-9136(199807)15:7<539::AIDDIA668>3.0.CO;2-S)

10 Balkau B \& Charles MA. Comment on the provisional report from the WHO consultation. European Group for the Study of Insulin Resistance (EGIR). Diabetic Medicine 199916 442-443. (https://doi. org/10.1046/j.1464-5491.1999.00059.x)

11 Expert Panel on Detection, Evaluation, and Treatment of High Blood Cholesterol in Adults. Executive Summary of The Third Report of The National Cholesterol Education Program (NCEP) Expert Panel on Detection, Evaluation, And Treatment of High Blood Cholesterol In Adults (Adult Treatment Panel III). JAMA 2001285 2486-2497. (https://doi.org/10.1001/jama.285.19.2486)

12 Grundy SM, Cleeman JI, Daniels SR, Donato KA, Eckel RH, Franklin BA, Gordon DJ, Krauss RM, Savage PJ, Smith SC Jr et al. Diagnosis and management of the metabolic syndrome: an American Heart Association/National Heart, Lung, and Blood Institute Scientific Statement. Circulation 2005112 2735-2752. (https://doi.org/10.1161/ CIRCULATIONAHA.105.169404)

13 Alberti KG, Zimmet P \& Shaw J. Metabolic syndrome - a new worldwide definition. A Consensus Statement from the International Diabetes Federation. Diabetic Medicine 200623 469-480. (https://doi. org/10.1111/j.1464-5491.2006.01858.x)

14 Alberti KG, Eckel RH, Grundy SM, Zimmet PZ, Cleeman JI, Donato KA, Fruchart JC, James WP, Loria CM, Smith SC Jr et al. Harmonizing the metabolic syndrome: a joint interim statement of the International Diabetes Federation Task Force on Epidemiology and Prevention; National Heart, Lung, and Blood Institute; American Heart Association; World Heart Federation; International Atherosclerosis Society; and International Association for the Study of Obesity. Circulation 2009120 1640-1645. (https://doi.org/10.1161/ CIRCULATIONAHA.109.192644)

15 Holmer H, Ekman B, Bjork J, Nordstom CH, Popovic V, Siversson A \& Erfurth EM. Hypothalamic involvement predicts cardiovascular risk in adults with childhood onset craniopharyngioma on long-term GH therapy. European Journal of Endocrinology 2009161 671-679. (https:// doi.org/10.1530/EJE-09-0449)

16 Pereira AM, Schmid EM, Schutte PJ, Voormolen JH, Biermasz NR, van Thiel SW, Corssmit EP, Smit JW, Roelfsema F \& Romijn JA. High prevalence of long-term cardiovascular, neurological and psychosocial morbidity after treatment for craniopharyngioma. Clinical Endocrinology 200562 197-204. (https://doi.org/10.1111/j.13652265.2004.02196.x)

17 Simoneau-Roy J, O'Gorman C, Pencharz P, Adeli K, Daneman D $\&$ Hamilton J. Insulin sensitivity and secretion in children and adolescents with hypothalamic obesity following treatment for craniopharyngioma. Clinical Endocrinology 201072 364-370. (https:// doi.org/10.1111/j.1365-2265.2009.03639.x)

18 Profka E, Giavoli C, Bergamaschi S, Ferrante E, Malchiodi E, Sala E, Verrua E, Rodari G, Filopanti M, Beck-Peccoz P et al. Analysis of shortand long-term metabolic effects of growth hormone replacement therapy in adult patients with craniopharyngioma and non- functioning pituitary adenoma. Journal of Endocrinological Investigation 201538 413-420. (https://doi.org/10.1007/s40618-014-0196-0)

19 Sahakitrungruang T, Klomchan T, Supornsilchai V \& Wacharasindhu S. Obesity, metabolic syndrome, and insulin dynamics in children after craniopharyngioma surgery. European Journal of Pediatrics 2011 170 763-769. (https://doi.org/10.1007/s00431-010-1347-8)

20 Ferrau F, Spagnolo F, Cotta OR, Cannavo L, Alibrandi A, Russo GT, Aversa T, Trimarchi F \& Cannavo S. Visceral adiposity index as an indicator of cardiometabolic risk in patients treated for craniopharyngioma. Endocrine 2016 Epub. (https://doi.org/10.1007/ s12020-016-1196-y)

21 Blokstra A, Vissink P, Venmans LMAJ, Holleman P, van der Schouw YT, Smit HA \& Verschuren WMM. Measuring the Netherlands. A Monitoring Study of Risk Factors in the General Population, 2009-2010, pp 1-29, 2011.

22 Hollman G \& Kristenson M. The prevalence of the metabolic syndrome and its risk factors in a middle-aged Swedish population - mainly a function of overweight? European Journal of Cardiovascular Nursing 20087 21-26. (https://doi.org/10.1016/j. ejcnurse.2007.05.003)

23 Attanasio AF, Mo D, Erfurth EM, Tan M, Ho KY, Kleinberg D, Zimmermann AG, Chanson P \& International Hypopituitary Control Complications Study Advisory Board. Prevalence of metabolic syndrome in adult hypopituitary growth hormone (GH)-deficient patients before and after GH replacement. Journal of Clinical Endocrinology and Metabolism 201095 74-81. (https://doi. org/10.1210/jc.2009-1326)

24 Verhelst J, Mattsson AF, Luger A, Thunander M, Goth MI, KoltowskaHaggstrom M \& Abs R. Prevalence and characteristics of the metabolic syndrome in 2479 hypopituitary patients with adult-onset GH deficiency before GH replacement: a KIMS analysis. European Journal of Endocrinology 2011165 881-889. (https://doi.org/10.1530/EJE-11-0599)

25 Harz KJ, Muller HL, Waldeck E, Pudel V \& Roth C. Obesity in patients with craniopharyngioma: assessment of food intake and movement counts indicating physical activity. Journal of Clinical Endocrinology and Metabolism 200388 5227-5231. (https://doi.org/10.1210/jc.2002021797)

26 Piguel X, Abraham P, Bouhours-Nouet N, Gatelais F, Dufresne S, Rouleau S \& Coutant R. Impaired aerobic exercise adaptation in children and adolescents with craniopharyngioma is associated with hypothalamic involvement. European Journal of Endocrinology 2012 166 215-222. (https://doi.org/10.1530/EJE-11-0742)

27 He D, Xi B, Xue J, Huai P, Zhang M \& Li J. Association between leisure time physical activity and metabolic syndrome: a meta-analysis of prospective cohort studies. Endocrine 201446 231-240. (https://doi. org/10.1007/s12020-013-0110-0)

28 Roth CL. Hypothalamic obesity in craniopharyngioma patients: disturbed energy homeostasis related to extent of hypothalamic damage and its implication for obesity intervention. Journal of Clinical Medicine 20154 1774-1797. (https://doi.org/10.3390/jcm4091774)

29 Muller HL, Bueb K, Bartels U, Roth C, Harz K, Graf N, Korinthenberg R, Bettendorf M, Kuhl J, Gutjahr P et al. Obesity after childhood craniopharyngioma - German multicenter study on pre-operative risk factors and quality of life. Klinische Padiatrie 2001213 244-249. (https://doi.org/10.1055/s-2001-16855)

30 Muller HL, Gebhardt U, Etavard-Gorris N, Korenke E, Warmuth-Metz M, Kolb R, Sorensen N \& Calaminus G. Prognosis and sequela in patients with childhood craniopharyngioma - results of HIT-ENDO and update on KRANIOPHARYNGEOM 2000. Klinische Padiatrie 2004 216 343-348. (https://doi.org/10.1055/s-2004-832339)

31 Mortini P, Gagliardi F, Bailo M, Spina A, Parlangeli A, Falini A \& Losa $\mathrm{M}$. Magnetic resonance imaging as predictor of functional outcome in craniopharyngiomas. Endocrine 201651 148-162. (https://doi. org/10.1007/s12020-015-0683-x)

32 Wijnen M, Olsson DS, van den Heuvel-Eibrink MM, Wallenius V, Janssen J, Delhanty PJ, van der Lely AJ, Johannsson G \& Neggers S. 
Efficacy and safety of bariatric surgery for craniopharyngioma-related hypothalamic obesity-A matched case-control study with two years of follow-up. International Journal of Obesity 201641 210-216. (https://doi. org/10.1038/ijo.2016.195)

33 Sullivan SD, Sarrel PM \& Nelson LM. Hormone replacement therapy in young women with primary ovarian insufficiency and early menopause. Fertility and Sterility 2016106 1588-1599. (https://doi. org/10.1016/j.fertnstert.2016.09.046)

34 Langrish JP, Mills NL, Bath LE, Warner P, Webb DJ, Kelnar CJ, Critchley HO, Newby DE \& Wallace WH. Cardiovascular effects of physiological and standard sex steroid replacement regimens in premature ovarian failure. Hypertension 200953 805-811. (https://doi. org/10.1161/HYPERTENSIONAHA.108.126516)

35 Johannsson G \& Ragnarsson O. Cardiovascular and metabolic impact of glucocorticoid replacement therapy. Frontiers of Hormone Research 201443 33-44. (https://doi.org/10.1159/000360556)

36 Ridker PM, Buring JE, Cook NR \& Rifai N. C-reactive protein, the metabolic syndrome, and risk of incident cardiovascular events: an 8-year follow-up of 14719 initially healthy American women. Circulation 2003107 391-397. (https://doi.org/10.1161/01. CIR.0000055014.62083.05)
37 Sattar N, Gaw A, Scherbakova O, Ford I, O'Reilly DS, Haffner SM, Isles C, Macfarlane PW, Packard CJ, Cobbe SM et al. Metabolic syndrome with and without C-reactive protein as a predictor of coronary heart disease and diabetes in the West of Scotland Coronary Prevention Study. Circulation 2003108 414-419. (https://doi.org/10.1161/01. CIR.0000080897.52664.94)

38 Gierach M, Gierach J, Ewertowska M, Arndt A \& Junik R. Correlation between body mass index and waist circumference in patients with metabolic syndrome. ISRN Endocrinology 20142014 514589. (https:// doi.org/10.1155/2014/514589)

39 Blijdorp K, van den Heuvel-Eibrink MM, Pieters R, Boot AM, Delhanty PJ, van der Lely AJ \& Neggers SJ. Obesity is underestimated using body mass index and waist-hip ratio in long-term adult survivors of childhood cancer. PLoS ONE 20127 e43269. (https://doi.org/10.1371/ journal.pone.0043269)

40 Demmer DL, Beilin LJ, Hands B, Burrows S, Cox KL, Pennell CE, Lye SJ, Mountain JA \& Mori TA. Dual energy X-ray absorptiometry compared with anthropometry in relation to cardio-metabolic risk factors in a young adult population: is the 'gold standard' tarnished? PLOS ONE 201611 e0162164. (https://doi.org/10.1371/ journal.pone.0162164)

Received 11 May 2017

Revised version received 22 August 2017

Accepted 7 September 2017 